\title{
Characteristics of Plasma Polymerized Low-dielectric Constant SiCOH Films Deposited with Tetrakis(trimethylsilyloxy)silane and Cyclohexane Precursors
}

\author{
Hoonbae Kim, Hyojin Oh, ${ }^{\dagger}$ Chaemin Lee, Donggeun Jung, ${ }^{*}$ and Jin-Hyo Boo ${ }^{\ddagger}$, \\ Department of Physics, Sungkyunkwan University, Suwon 440-746, Korea. *E-mail: djung@skku.ac.kr \\ ${ }^{\dagger}$ Foundry Business Team, Samsung Electronics, Yongin 446-711, Korea \\ *Department of Chemistry, Sungkyunkwan University, Suwon 440-746, Korea.*E-mail: jhboo@skku.edu \\ Received May 20, 2014, Accepted June 8, 2014
}

\begin{abstract}
The electrical and mechanical properties of the plasma polymerized low dielectric constant SiCOH films were investigated. The SiCOH films were produced with tetrakis(trimethylsilyloxy)silane and cyclohexane as precursors by using a plasma enhanced chemical vapor deposition. When the deposition plasma powers were changed from 10 to $50 \mathrm{~W}$, the relative dielectric constant of the SiCOH film increased from 2.09 to 2.76 and their hardness and elastic modulus were changed from 1.6 to $5.6 \mathrm{GPa}$ and from 16 to $44 \mathrm{GPa}$, respectively. After thermal annealing at $500{ }^{\circ} \mathrm{C}$, the annealed $\mathrm{SiCOH}$ films showed relative dielectric constants of 1.80-2.97, a hardness of 0.45-0.6 GPa and an elastic modulus of 6-7 GPa. And then, the chemical structures of asdeposited and annealed SiCOH films were analyzed by using Fourier transform infrared spectroscopy.
\end{abstract}

Key Words : Low dielectric constant, Plasma enhanced chemical vapor deposition, Fourier transform infrared spectroscopy, Hardness, Elastic modulus

\section{Introduction}

In the manufacture of integrated circuits (ICs), one of the important steps is the formation of metal and interlayer dielectric (ILD) films. Usually, the ILD films were produced by a chemical vapor deposition (CVD), ${ }^{1-3}$ which is a good method to shrink the feature size of circuit. Among the CVD methods, the plasma enhanced $\mathrm{CVD}^{4}$ (PECVD), in which dielectric films are deposited at a relatively low temperature, has been used in many cases. However, ICs with silicon dioxide $\left(\mathrm{SiO}_{2}\right)$, which has been mainly used as an ILD film, show high resistance $\times$ capacitance $(R C)$ delay times, especially when ultra large scale ICs of $0.5 \mu \mathrm{m}$ or less are manufactured. In order to reduce the $R C$ delay, $\operatorname{copper}(\mathrm{Cu})$ damascene interconnects with low relative dielectric constant (low- $k ; k \leq 3.0$ ) have been continuously conducted. ${ }^{5,6}$ Such ILD films having low dielectric constants are mostly applied either with fluorine $(\mathrm{F})$-doped materials such as F-doped oxide (SiOF) films and F-doped amorphous carbon (a-C:F) films, ${ }^{7,8}$ or with $\mathrm{SiCOH}$ films containing silicon $(\mathrm{Si})$, carbon (C), oxygen $(\mathrm{O})$ and hydrogen $(\mathrm{H}){ }^{7}$ Especially, the PECVDdeposited low- $k$ SiCOH films have been strongly regarded as the potential ILD film due to relatively low dielectric constants and easiness to be applied to the present manufacturing system, etc.

In the material processing of low- $k \mathrm{SiCOH}$ films, the key issue is the trade-off between dielectric constant and mechanical strength of low- $k$ SiCOH films. ${ }^{9}$ The incorporation of nano-pores by removing unstable organic fragments using a thermal annealing process could generally reduce the dielectric constant of film. However, if the size of pores was large and/or the pores were not distributed uniformly within the low- $k$ SiCOH films, the hardness and elastic modulus could be decreased. Therefore, it is very important to characterize and optimize the electrical and mechanical properties of low- $k$ SiCOH films. ${ }^{10,11}$

In this work, we prepared the low- $k$ SiCOH films by using PECVD with the variation of deposition plasma power. The dielectric constant, hardness and elastic modulus of asdeposited and annealed SiCOH films were investigated. And their properties were correlated with chemical structures.

\section{Experimental}

The low- $k$ SiCOH films were fabricated by PECVD system using tetrakis(trimethylsilyloxy)silane $\left(\mathbf{S i}_{5} \mathbf{C}_{\mathbf{1 2}} \mathbf{O}_{\mathbf{4}} \mathbf{H}_{\mathbf{3 6}}\right)$, referred to as TTMSS, as a $\mathrm{Si}-\mathrm{O}$ precursor and cyclohexane $\left(\mathrm{C}_{6} \mathrm{H}_{12}\right)$, referred to as $\mathrm{CHex}$, as a main hydrocarbon precursor contained in separated bubblers, as the chemical structure is shown in Figure 1. The bubblers containing TTMSS and CHex were heated to $90{ }^{\circ} \mathrm{C}$ and $55^{\circ} \mathrm{C}$, respectively, vaporizing the precursor solutions. Using the helium (He) gas having ultra-high purity of $99.999 \%$ as a carrier gas, the vaporized precursors were sprayed on the Si substrate through the shower head of the reactor for plasma deposition. The deposition was performed at the reactor pressure of $6.6 \times 10^{-1}$ Torr, and at room temperature. The plasma power supplied by the radio frequency $(\mathrm{RF})$ generator was changed from 10 to $50 \mathrm{~W}$, and the plasma frequency was $13.56 \mathrm{MHz}$. The plasma polymerized thin film deposited using TTMSS and CHex precursors was referred to as ppTTMSS:CHex. After deposition, the ppTTMSS: CHex thin film was annealed using a rapid thermal annealing (RTA) system. The ppTTMSS:CHex thin film deposited on the Si substrate was placed in an RTA system, and heat was generated using 12 halogen lamps disposed around, and 
<smiles>C[Si](C)(C)O[Si](O[Si](C)(C)C)(O[Si](C)(C)C)O[Si](C)(C)C</smiles>

Figure 1. Chemical structure of TTMSS.

the ppTTMSS:CHex thin film was heat treated at $500{ }^{\circ} \mathrm{C}$ for 5 minutes, while the pressure of nitrogen ambient gas was set to 1.0 Torr.

The film thickness and hardness, elastic modulus were measured using a scanning electron microscope and nanoindentor, respectively. The capacitance of aluminum(Al)/ ppTTMSS:CHex/metalic-slicon (M-Si), i.e. metal/insulator/ metal (MIM) structure, was measured to calculate the dielectric constant. Finally, the chemical composition of ppTTMSS:CHex thin film was analyzed by using Fourier transform infrared (FT-IR) spectroscopy.

\section{Results and Discussion}

Figure 2 is a graph showing the deposition rate of the ppTTMSS:CHex thin film with the variation of deposition plasma power. It was verified that the deposition rate of the ppTTMSS:CHex thin film increased from 10.9 to $55.0 \mathrm{~nm} /$ min as the power supplied by the RF generator increased from 10 to $50 \mathrm{~W}$. It is considered that the power absorbed in the precursors would have a strong influence on dissociation of precursors, and higher deposition power caused the increase of deposition rate. ${ }^{12,13}$

And the relative dielectric constant $(k)$ values of the asdeposited and annealed ppTTMSS:Chex thin film were measured and shown in Figure 3 . The $k$ value of as-deposited ppTTMSS:CHex thin film increased from 2.09 to 2.76 with increase of the deposition plasma power, and the

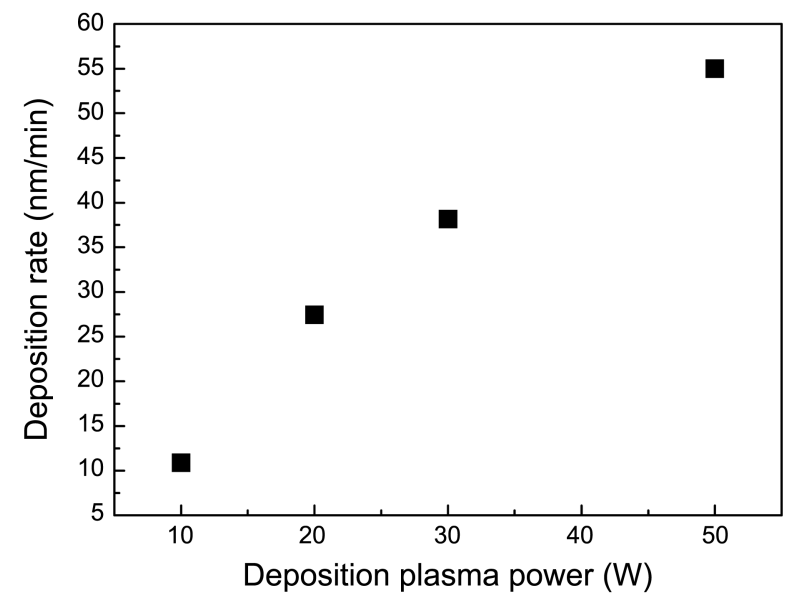

Figure 2. Deposition rate of ppTTMSS:CHex films as a function of deposition plasma power.

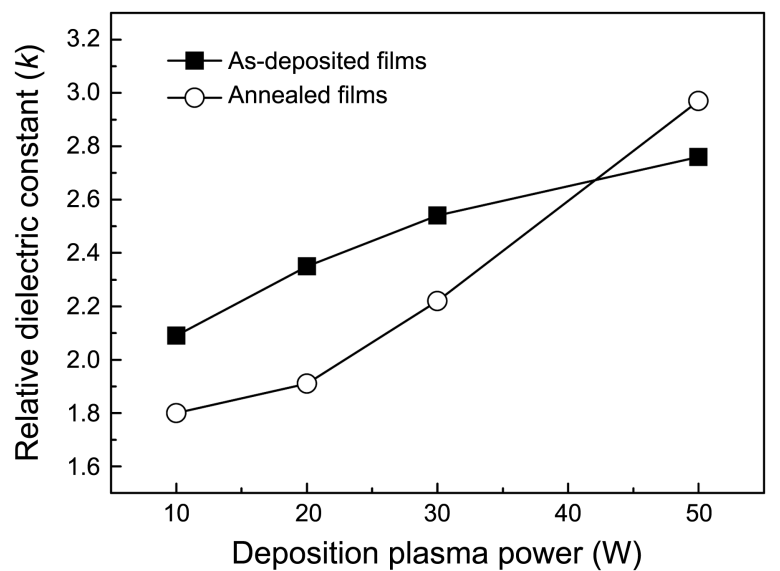

Figure 3. Relative dielectric constant of as-deposited and annealed ppTTMSS:CHex thin films with various deposition plasma powers.

annealed ppTTMSS:CHex thin film showed the $k$ value of 1.80-2.97. It is thought that the increase of deposition plasma power caused an increase of ion bombardment on to the surface of a growing film and an increase in cross-linking of film, and thus the SiCOH film became denser. The denser film is generally thought to have a higher $k$ value. After annealing at $500{ }^{\circ} \mathrm{C}$, the hydrocarbon removal in the film
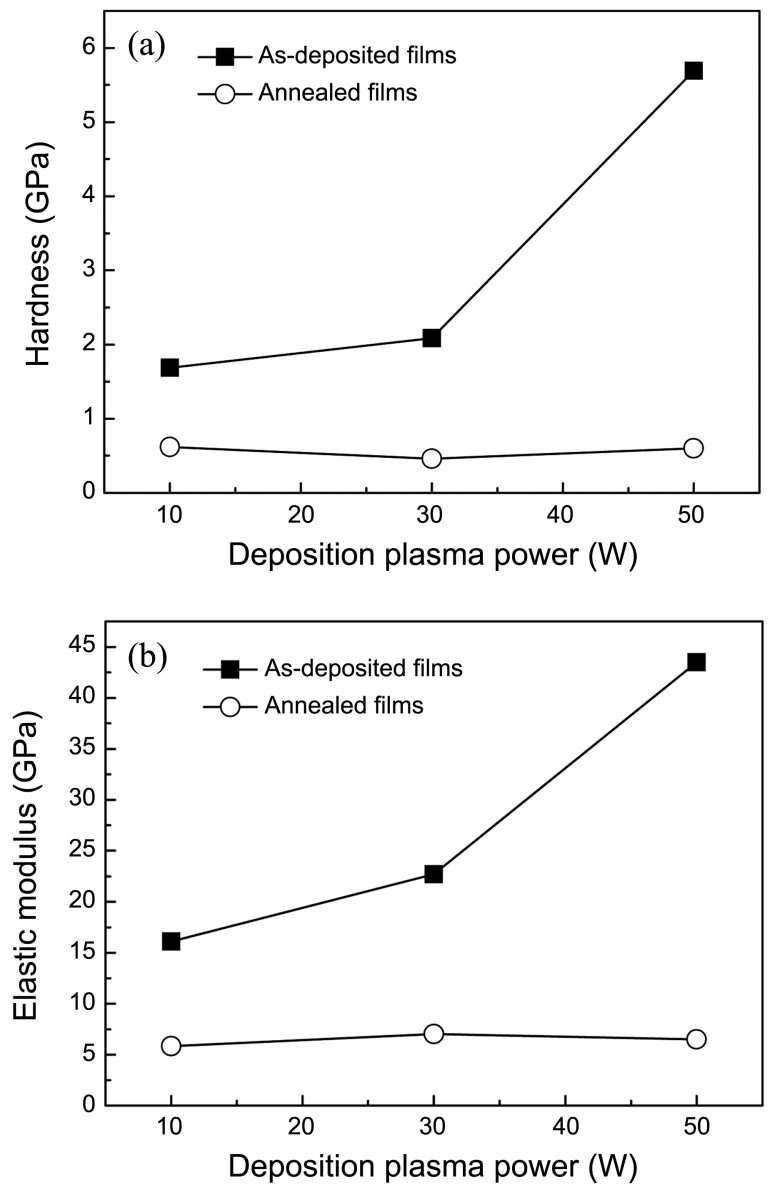

Figure 4. (a) Hardness and (b) elastic modulus of as-deposited and annealed ppTTMSS:CHex thin films with various deposition plasma powers. 
would lead to reduction of dielectric constants. ${ }^{14}$

The hardness and the elastic modulus for the as-deposited and annealed ppTTMSS:CHex thin films were measured using a nano-indenter and shown in Figures 4(a) and (b). The hardness of the ppTTMSS:CHex thin films increased from 1.6 $\mathrm{GPa}$ to $5.6 \mathrm{GPa}$ as the deposition plasma power increased, and the elastic modulus also increased from 16 $\mathrm{GPa}$ to $44 \mathrm{GPa}$. The hardness and elastic modulus of the annealed ppTTMSS:CHex thin film showed decrease to 0.45-0.6 GPa and 6-7 GPa, respectively.

For the as-deposited and annealed ppTTMSS:CHex thin films, the chemical structures were studied by FT-IR spectra in the wave number range from 4000 to $500 \mathrm{~cm}^{-1}$, and the results are shown in Figure 5 with various deposition plasma powers. These spectra were normalized to the same thickness. Peaks at approximately $3200-2800 \mathrm{~cm}^{-1}$ are from C-H $(\mathrm{x}=2,3)$ stretching vibrations. Peaks at approximately $1500-1350 \mathrm{~cm}^{-1}$ are due to $\mathrm{C}-\mathrm{H}_{\mathrm{x}}(\mathrm{x}=2,3)$ related bending vibration modes, and those at $1240-1300 \mathrm{~cm}^{-1}$ are from the $\mathrm{Si}-\mathrm{CH}_{3}$ bending mode. The peaks at around 1240 to 950 $\mathrm{cm}^{-1}$ are from the $\mathrm{Si}-\mathrm{O}$ related stretching vibration modes. The broad absorption band between 950 and $650 \mathrm{~cm}^{-1}$ corresponds to $\mathrm{H}-\mathrm{Si}-\mathrm{O}$ and $\mathrm{Si}-\mathrm{Me}_{\mathrm{x}}\left(\mathrm{CH}_{3}\right)(\mathrm{x}=1,2,3)$ bend-
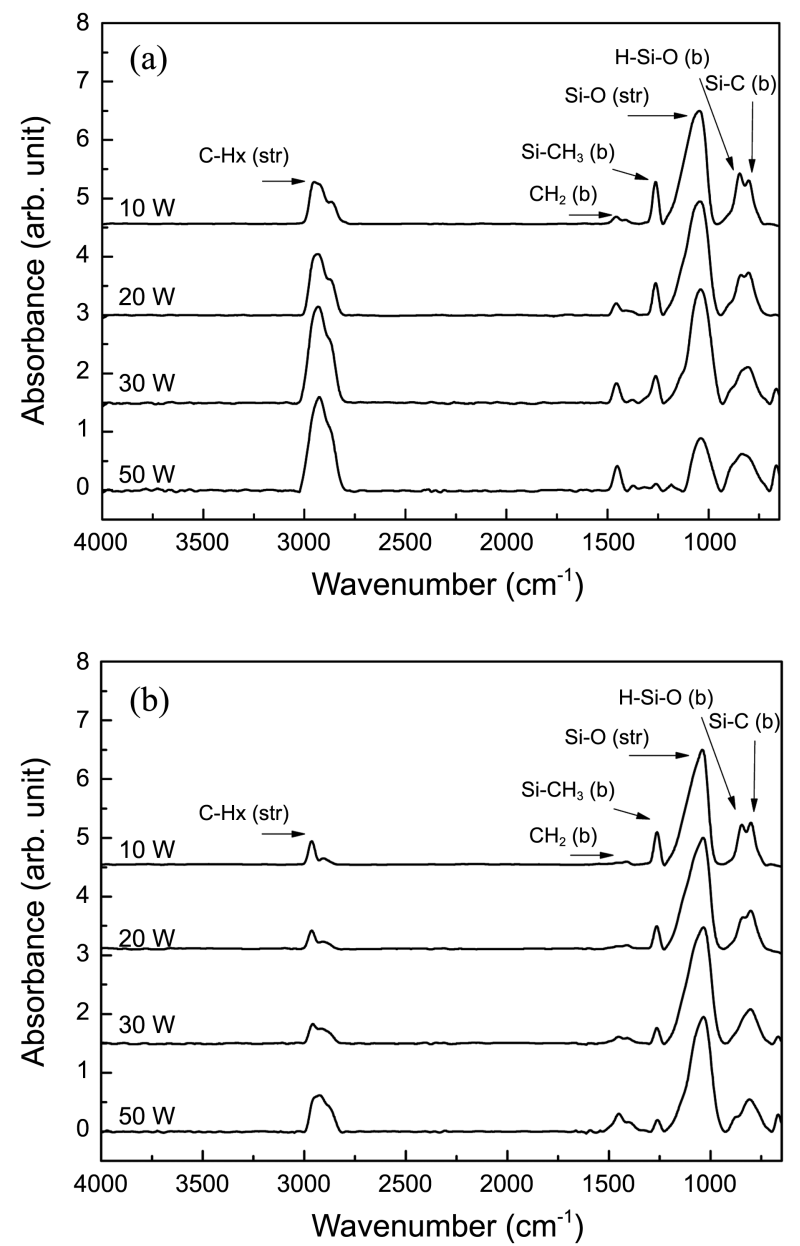

Figure 5. FT-IR absorption spectra from (a) as-deposited and (b) annealed ppTTMSS:CHex thin films deposited with various deposition plasma powers. ing vibration. ${ }^{15}$ Basically, $\mathrm{C}-\mathrm{H}_{\mathrm{x}}$ (hydrocarbon) and $\mathrm{Si}-\mathrm{O}$ bonding structure are the majority in the ppTTMSS:CHex thin film, as shown in the Figure 5. In particular, when the deposition plasma powers were increased, the amounts of hydrocarbon increased, as shown by increased peak intensities of $\mathrm{C}-\mathrm{H}_{\mathrm{x}}$.

Figure 6 shows the $I\left(\mathrm{C}-\mathrm{H}_{\mathrm{x}}\right) / I(\mathrm{Si}-\mathrm{O})$ of FT-IR absorption spectra from as-deposited and annealed ppTTMSS:CHex films with various deposition plasma powers, where $I(\mathrm{C}$ $\left.\mathrm{H}_{\mathrm{x}}\right) /\left(\mathrm{I}(\mathrm{Si}-\mathrm{O})\right.$ is the ratio of the $\mathrm{C}-\mathrm{H}_{\mathrm{x}}$ stretching peak area to the $\mathrm{Si}-\mathrm{O}$ stretching peak area. The $I\left(\mathrm{C}-\mathrm{H}_{\mathrm{x}}\right) / I(\mathrm{Si}-\mathrm{O})$ was increased from 0.3 to 2.4 with increase of deposition plasma power. For deposition plasma power $\geq 30 \mathrm{~W}$, the $I\left(\mathrm{C}-\mathrm{H}_{\mathrm{x}}\right) /$ I(Si-O) of ppTTMSS:CHex showed drastic increment. The changing of $I\left(\mathrm{C}-\mathrm{H}_{\mathrm{x}}\right) / I(\mathrm{Si}-\mathrm{O})$ coincide with increase of hardness and modulus as a function of deposition plasma power. The peak intensities of hydrocarbon in our ppTTMSS:CHex films are much higher than those reported in our previous work $^{15,16}$ and other low- $k$ SiCOH works. ${ }^{14,17}$ It is even higher than intensity of $\mathrm{Si}-\mathrm{O}$ related stretching vibration for the deposition plasma power of $50 \mathrm{~W}$. The high intensity of hydrocarbon would be deduced from structure of precursors. The TTMSS has a structure of cross shape, in which a $\mathrm{Si}$ atom at the center is linked to oxygen atoms in four directions. The four trimethylsilyl $\left(\mathrm{Si}\left(\mathrm{CH}_{3}\right)_{3}\right)$ groups are bonded to four oxygen atoms. It is thought that this structure of TTMSS with four branches would enhance the cross-linking among species derived by plasma from TTMSS and/or CHex molecules. In addition, the ppTTMSS:CHex deposited with plasma power of $50 \mathrm{~W}$ have highest hardness and elastic modulus, similar to $\mathrm{SiO}_{\mathrm{x}}$ containing diamond like carbon $\left(\mathrm{SiO}_{\mathrm{x}}: \mathrm{DLC}\right){ }^{18}$ It is thought that higher contents of hydrocarbon species in the ppTTMSS:CHex films result in higher portions of $\mathrm{SiO}_{\mathrm{x}}$ :DLC materials, which are reported to have high hardness and modulus. ${ }^{18-20}$ This may explain our ppTTMSS:CHex films with higher hydrocarbon content show enhanced mechanical properties.

However, the annealed thin film had a relatively higher $\mathrm{Si}$ $\mathrm{O}$ bonding structure compared to a $\mathrm{C}-\mathrm{H}_{\mathrm{x}}$ bonding structure. As shown in Figure 3 and Figure 4, it was shown that after

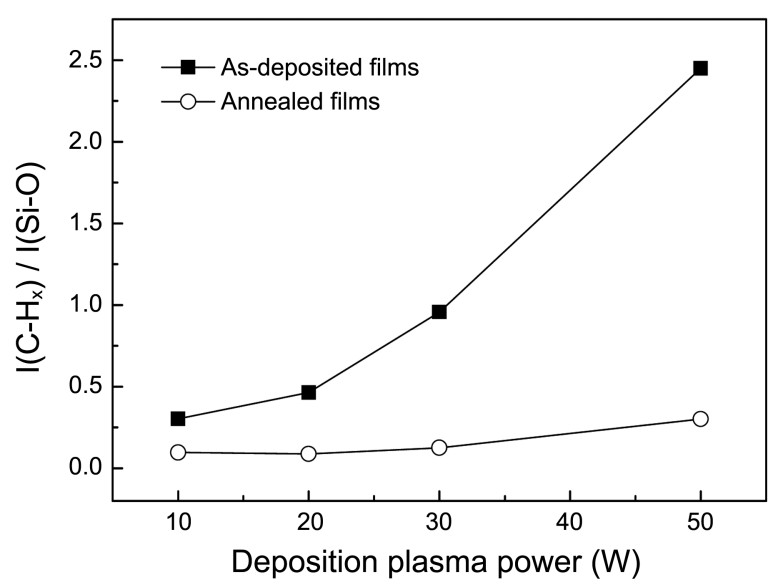

Figure 6. $I\left(\mathrm{C}-\mathrm{H}_{\mathrm{x}}\right) / I(\mathrm{Si}-\mathrm{O})$ of FT-IR spectra from as-deposited and annealed ppTTMSS:CHex. 
annealing the dielectric constant generally decreased and the hardness and elastic modulus of the thin film was also reduced, and it is considered that the mechanical properties of the thin film was more or less reduced by the pores being formed where the hydrocarbon was sublimated, as the hydrocarbon was sublimated due to the heat treatment. ${ }^{21,22}$

\section{Conclusions}

The low- $k$ SiCOH film was prepared using a PECVD system with TTMSS and CHex as precursors. The electric and mechanical properties of as-deposited and annealed ppTTMSS:CHex thin film deposited with various plasma powers were characterized. Deposition rate, relative dielectric constant, hardness and elastic modulus of ppTTMSS:CHex thin film were increased from $10.88 \mathrm{~nm} / \mathrm{min}, 2.09,1.6 \mathrm{GPa}$ and $16 \mathrm{GPa}$ to $55.00 \mathrm{~nm} / \mathrm{min}, 2.76,5.6 \mathrm{GPa}$ and $44 \mathrm{GPa}$, respectively, when the deposition plasma power increased from 10 to $50 \mathrm{~W}$. Electric and mechanical properties of 500 ${ }^{\circ} \mathrm{C}$ RTA annealed ppTTMSS:CHex thin films showed overall reduction. The annealed ppTTMSS:CHex thin film showed the $k$ value of 1.80-2.97. The hardness and elastic modulus of the annealed ppTTMSS:CHex thin film showed decrease to $0.45-0.6 \mathrm{GPa}$ and 6-7 GPa, respectively, as compared with as-deposited ppTTMSS:CHex thin film. From the FT-IR spectroscopy, it was shown that the hardness and elastic modulus decreased as the decrease of hydrocarbon amount in the ppTTMSS:CHex thin film.

Acknowledgments. This work was supported by the Human Resources Development program (No. 20124010203280) of the Korea Institute of Energy Technology Evaluation and Planning (KETEP) grant funded by the Korea government Ministry of Trade, Industry and Energy and by Basic Science Research Program through the National Research Foundation of Korea (NRF) funded by the Ministry of Education (2009-0094023).

\section{References}

1. Wolf, S.; Tauber, R. N. Silicon Processing for the VLSI Era: Process Technology, 2nd ed.; Lattice Press: California, USA, 2000; Vol. 1.

2. Adams, A. C. Dielectric and Polysilicon Film Deposition in VLSI Technology; Sze, S. H., Ed.; McGraw Hill: New York, USA, 1983; p 93.

3. Sivaram, S. Chemical Vapor Deposition; McGraw Hill: New York, USA, 1995

4. Yasuda, H. Plasma Polymerization; Academic Press: New York, USA, 1985.

5. Gupta, T. Copper Interconnect Technology; Springer: Heidelberg, Germany, 2009.

6. Fang, Z. Q.; Claflin, B.; Look, D. C.; Farlow, G. C. J. Electron. Mater. 2007, 36, 307.

7. Kim, Y. H.; Hwang, M. S.; Kim, H. J.; Kim, J. Y.; Lee, Y. J. Appl. Phys. 2001, 90, 3367

8. Endo, K.; Shinoda, K.; Tatsumi, T. J. Appl. Phys. 1999, 86, 2739.

9. Sekhar, V. N. Nanoindentation in Materials Science; InTech Press: Rijeka, Croatia, 2012; chapter 10.

10. Oh, T. J. Ceram. Process Res. 2010, 11, 648 .

11. Shen, L.; Zeng, K.; Wang Y.; Narayanan, B.; Kumar, R. Microelectron. Eng. 2003, 70, 115.

12. Biederman, H. Plasma Polymer Films; Imperial College Press: London, U.K. 2004; p 38.

13. Alexandrov, S. E.; Mcsporran, N.; Hitchman, M. L. Chem. Vap. Deposition 2005, 11, 481.

14. Grill, A.; Neumayer, D. A. J. Appl. Phys. 2003, 94, 6697.

15. Lee, S.; Woo, J.; Nam, E.; Jung, D.; Yang, J.; Chae, H.; Kim, H. Jpn. J. Appl. Phys. 2009, 48, 106001.

16. Yang, J.; Lee, S.; Park, H.; Jung, D.; Kim, H. J. Vac. Sci. Technol. A 2006, 24, 165.

17. Grill, A. Appl. Phys. 2003, 93, 1785.

18. Buršíkóvá, V.; Navrátil, V.; Zajíčková, L.; Janča, J. Mater. Sci. Eng. A-Struct. Mater. Prop. Microstruct. Process 2002, 324, 251.

19. Schiffmann, K. I.; Hieke, A. Wear 2003, 254, 565.

20. Yang, W. J.; Choa, Y. H.; Sekino, T.; Shim, K. B.; Niihara, K.; Auh, K. H. Thin Solid Films 2003, 434, 49.

21. Favennec, L.; Jousseaume, V.; Gerbaud, G.; Zenasni, A.; Passemard, G. J. Appl. Phys. 2007, 102, 064107.

22. Burkey, D. D.; Gleason, K. K.; J. Vac. Sci. Technol. A 2004, 22, 61. 